\title{
Care of the frail elderly in the community: a critical incident study
}

Louise Robinson and Chris Drinkwater Department of Primary Health Care, The Medical School, University of Newcastle upon Tyne, Newcastle upon Tyne, UK

\begin{abstract}
The aim of this qualitative study was to explore the process of care provided by a community-based geriatric assessment and management team (the elderly resource team or ERT) through a critical incident approach. Cases were discussed both with the ERT alone and in combined discussions with referring primary health care teams, using an external facilitator. Data analysis was based on the critical incident technique and a grounded theory approach. Analysis of 11 cases generated a total of 496 events (a mean of 45 events per case). The numbers of positive events and negative events (areas of concern) were approximately equal (236 and 260, respectively). Certain important themes emerged from the data to describe how the elderly resource team managed their patients. Patients were often referred for covert reasons, such as negative emotions in informal and formal carers and inappropriate demands on them. Integrated multidisciplinary assessment by the team generated a realistic appraisal of the situation. With time, the key worker became a trusted professional, leading to recognition of the patient's poor psychological adjustment to their illness, and unexpected breakthroughs in their management, which previous carers had been unable to achieve. Reflection of these concepts back to informal and formal carers was considered to be supportive. Caring for such complex patients also produced negative emotions in the elderly resource team. Internal support for individuals in such teams can be offered via the concept of role transference. Through further analysis using a grounded theory approach, a conceptual model was developed to describe the process of care delivered. This model requires further testing in order to determine whether it is applicable to other multidisciplinary rehabilitation teams.
\end{abstract}

Key words: community care; critical incident; geriatric assessment; multidisciplinary teams; rehabilitation

\section{Introduction}

An increasing elderly population and the development of a primary care-led National Health Service (NHS Executive, 1994) has led to a more complex and frail group of patients being cared for largely in the community. With the introduction of the Community Care Act in 1993 (Department of Health, 1990), skilled and integrated multidiscipli-

Address for correspondence: Dr Louise Robinson, Department of Primary Health Care, The Medical School, University of Newcastle upon Tyne, Newcastle upon Tyne NE2 4HH, UK. Email: a.1.robinson@newcastle.ac.uk

(C)Arnold 2000 nary assessment of the health and social needs of this group of people was considered to be essential (Standing Medical Advisory Committee, 1990). However, the present structures of health and social services, with separate lines of funding, different accountabilities and variable models of interprofessional and interagency working, present an obstacle to achieving such seamless care. The creation of community-based elderly assessment and management teams provides one solution to this problem (Stuck et al., 1993). Although the cost-effectiveness of such an innovative service provision compared to traditional methods of secondary elderly care has not been established, initial 1463-4236(2000)PC022OA 
evaluation of this model has shown high levels of patient/carer satisfaction, reduced carer strain and a reduction in rates of hospital admission and institutionalization (Stuck et al., 1993; MacMahon, 1994).

In 1995, Newcastle and North Tyneside Health Authorities funded the development of a community-based assessment and management team for the care of the frail elderly in one locality of Newcastle upon Tyne. The elderly resource team (ERT) includes health professionals from primary health care (a general practitioner and community liaison nurse), secondary care (a geriatrician, occupational therapist, rehabilitation assistant and speech therapist), and community services (a social worker, physiotherapist and chiropodist). The aims of the team are to provide easier access to and better co-ordination of assessment and rehabilitation of elderly people in the community, to improve support in the management of patients in residential and nursing homes, and to provide education and support to both informal and formal carers. Referrals can be made by any member from the primary health care team or secondary care, provided that the patient's general practitioner is informed. Following referral, an initial assessment visit is made by one member of the team, and the patient is then allocated a key worker from the team to oversee and co-ordinate subsequent care. The team meets weekly to discuss and review patients. Where possible, patients are assessed and managed entirely in their own homes.

The use of multidisciplinary health care teams is an increasingly common aspect of service provision in health care in Western countries (Mellor and Solomon, 1992). In the UK, community-based rehabilitation teams consisting of members from primary, secondary and community care have been recommended as a model for the future management of patients with chronic illness and disability (Working Group of the Royal College of Physicians Rehabilitation Medicine Committee, 1997), with the creation of specialist teams focused on a particular problem, such as a stroke rehabilitation team. Currently there is an absence of documented research describing and analysing such teams in action (Sands, 1993). Instead, the literature concentrates on anecdotal evidence and interpersonal dynamics within teams (Gregson et al., 1991; Sands, 1993). The aim of this qualitative study was to explore the process of care provided by one such multidisciplinary team, namely the elderly resource team, using a critical incident approach.

\section{Methods}

\section{The critical incident technique and facilitated case discussion}

The critical incident technique is a systematic, inductive method for eliciting behavioural data based on observers' accounts of actual critical events (incidents) rather than anecdote or opinion (Flanagan, 1954). To be 'critical', the incident must make a 'significant contribution either positively or negatively to the purpose of the act' (Flanagan, 1954). Analysis in critical incident studies takes place via inductive classification of the data and construction of a hierarchy of categories. Further incidents are collected until no further categories appear to emerge from the data. This technique has been used extensively to develop taxonomies of competence in medicine (Waterston, 1988), nursing (Benner, 1984; Norman et al., 1992) and other health professions (Dunn and Hamilton, 1986). It has also been employed in primary care as a means of qualitative research, to analyse doctors' prescribing behaviour (Bradley, 1992b), and as a method for multidisciplinary audit (Pringle et al., 1995; Robinson et al., 1995). In the latter case, the technique has been modified and the methodology termed significant event audit (Pringle et al., 1995) or facilitated case discussion (Robinson et al., 1995).

\section{Selection and recruitment of practices}

Six of the 13 practices in the locality making referrals to the ERT were randomly selected after stratification for list size and involvement in undergraduate teaching and vocational training. Using this procedure it was hoped to achieve a mix of practices with regard to both size and character (Baker et al., 1995). Six practices were chosen as the study was to be held over a 6-month period and the ERT considered this to be the maximum number they could meet during this period. Recruitment of the practices was achieved through visits from the GP facilitator and a selection of members of the ERT to discuss the study. Two practices declined to participate because of ongoing involvement in audit studies. The remaining four practices in the locality of similar size to these

Primary Health Care Research and Development 2000; 1: 163-177 
two were visited but also declined to take part. The four participating practices (practices A, B, C and D) varied in size, with patient lists ranging from 3751 to 11777 in size. Three practices were involved in undergraduate teaching and one was involved in vocational training. Three held regular primary health care team meetings to which all employed and attached staff were invited. Two practices were fundholders, and two had previous experience of facilitated case discussion (Berlin et al., 1992; Spencer et al., 1995).

\section{The case discussions}

Initially the ERT undertook a pilot discussion of a significant case in order to familiarize themselves with the methodology (Robinson et al., 1995). The ERT agreed to discuss cases both as a team and with referring primary health care teams; the former would provide an in-depth review of team function, while the latter would provide a review of issues at the primary-secondary care interface. One hour was allowed for each case discussion. The discussions were audiotaped, transcribed verbatim and the written record anonymized. The format for the discussions followed previously published guidelines (Robinson et al., 1995). The ERT selected cases that they considered to be critical or significant - either those that they felt positive about or those which had caused or were still causing them anxiety or concern. In the combined discussions, each practice selected three cases which they considered to be critical or significant, and from these the ERT prioritized two for discussion and the three most relevant professionals to participate in order to maintain an effective group size (between 10 and 12) (Robinson et al., 1995). In meetings with the ERT alone, the discussion began with the key worker for the patient recounting why the case was chosen and describing his or her personal recollections of the case. In combined meetings with the practices, the discussion started with the person who had referred the patient. Participants were asked to highlight aspects of behaviour which they considered to be effective or ineffective.

\section{Data analysis}

Each transcript was analysed by the external facilitator (LR) with data grouped and coded using the critical incident technique (Flanagan, 1954) and grounded theory methodology (Strauss and
Corbin, 1990). Through the process of open coding, selected metaphors and phrases were highlighted in the transcript and interpretative observations (concepts) inserted alongside. The concepts were systematically compared and expanded into broader categories with further observations classified into either previously identified categories or newly emerging ones. Review of the first three case transcripts by an independent researcher ensured the reliability of this analysis. An example of part of a transcript analysis is shown in Appendix 1 .

A schema for categorizing incidents was devised after analysis of the first seven discussions. Subsequent cases were selected to confirm or refute the developed theory. Discussions were continued until the ERT and facilitator agreed that no new categories were arising from the analysis. Concepts and categories were confirmed, modified or discarded from ongoing analysis by re-examination of the existing data and during subsequent data collection and analysis. All of the transcripts were reviewed by the facilitator again at the end of the study in order to validate the assignment of events to categories, their frequency, and to test the developed theory against individual cases. From this an inductive classification of categories and subcategories which were considered to be important in the management approach of the ERT was generated following Flanagan's principles (Flanagan, 1954).

The categories and subcategories were then linked according to the following grounded theory paradigm: causal conditions $\rightarrow$ core phenomenon $\rightarrow$ context $\rightarrow$ actions/interactions $\rightarrow$ consequences and outcomes (Strauss and Corbin, 1990). One category, namely that of role transference, was selected as the central or core phenomenon. This category appeared to the facilitator to encompass the process occurring at all levels (between carers and referrers, between referrers and the ERT, and within the ERT) in patient management. Other categories were linked to the core category following the above paradigm, initially through narrative development and then in diagrammatic form.

\section{Respondent validation}

After each discussion, an immediate verbal summary was provided by the facilitator and a written sheet was later sent to participants after each data analysis. Two review sessions were held with the 
ERT, the first after seven case discussions and the second at the end of the discussions in order to establish that the data had been fully and accurately interpreted.

\section{Results}

\section{Characteristics of the cases discussed}

A total of 11 cases were discussed in total, four with the ERT alone and seven in combined discussion with the practices (see Table 1). Practice $\mathrm{C}$ was able to discuss only one case due to pressure of practice business. The majority of the cases discussed were female (10 female: 1 male), with a mean age of 80 years (range 71-90 years).

\section{Attendance at facilitated case discussions}

For discussions involving the ERT alone, the mean number of participants was 4 (range 3-6). During the study, the part-time speech therapist went on maternity leave and the community nurse acquired a managerial position. The general practitioner in the ERT held a purely administrative role, but was also a partner in practice $\mathrm{A}$, and so only participated in practice discussions. For the combined discussions with the practices, the mean number of participants was 9 (range 7-12), with a mean of 3 ERT members and 7 primary health care team members. From the primary health care team, the mean number of doctors involved was 4 (range 2-6) and the mean number of nurses was 3 (range $1-5)$.

\section{Coding and categorization of significant events}

Analysis of 11 cases generated a total of 496 events (a mean of 45 events per case, range 3069). Discussions with the ERT alone generated a greater number of events (mean of 58 events per case, range 44-69) than discussions with the practices (mean 38, range 30-50). The major coding categories are shown in Table 2. Events were classified into categories relating to the ERT, to patients and carers, to the primary health care team and to secondary or external agencies. The numbers of positive points and concerns were approximately equal (236 and 260, respectively). The major categories in the positive events were clinical care by the elderly resource team $(n=88)$, patient/carer outcomes $(n=34)$, communication in and by the elderly resource team $(n=24)$, clinical care by the primary health care team, and professional support by the elderly resource team $(n=16)$. The major categories in the negative events were patient issues $(n=75)$, clinical care by the elderly resource team $(n=41)$, carer issues $(n=30)$ and feelings in the elderly resource team $(n=28)$. An example from the detailed schema of the coding classification is shown in Table 3.

\section{Turning data into theory - a conceptual model to explain the theoretical process of care provided by the ERT}

Certain important themes emerged from the data to interpret how the ERT managed their patients. Role transference was selected as the central category because this appeared to represent the core phenomenon occurring at all management levels. Patients generated negative emotions in both their informal and formal carers. This was handled through referral to the resource team where a similar situation resulted. However, the team attempted to deal with this constructively through internal role transference, before transferring the caring role back to the original carers.

A number of significant causal conditions were identified which contributed to the instigation of role transference. Primary health care teams referred patients with complex, interlinked medical and social problems. Such patients appeared to have difficulty in coming to terms psychologically with their disabilities (poor psychological adjustment to illness; see Box 1), leading to patient-carer

Box 1 Poor psychological adaptation of patient to illness

Case discussion E1:

I think $X$ was aware of that and also we were all trying and we gave her suggestions and she was blocking a lot of things that could be done to help but she was aware of that. There was an awful lot of emotion there, an awful lot of emotional baggage in her relationship with her husband and the stress she was putting on him. She knew everything that was going on and the last thing we offered was a referral to a psychologist.... She had not adjusted well to the illness, it really depressed her. She was a very dignified lady... she was embarrassed at going outside and people seeing that she was ill; she was very embarrassed about that and found it very difficult to come to terms with.

(Chiropodist, ERT) 


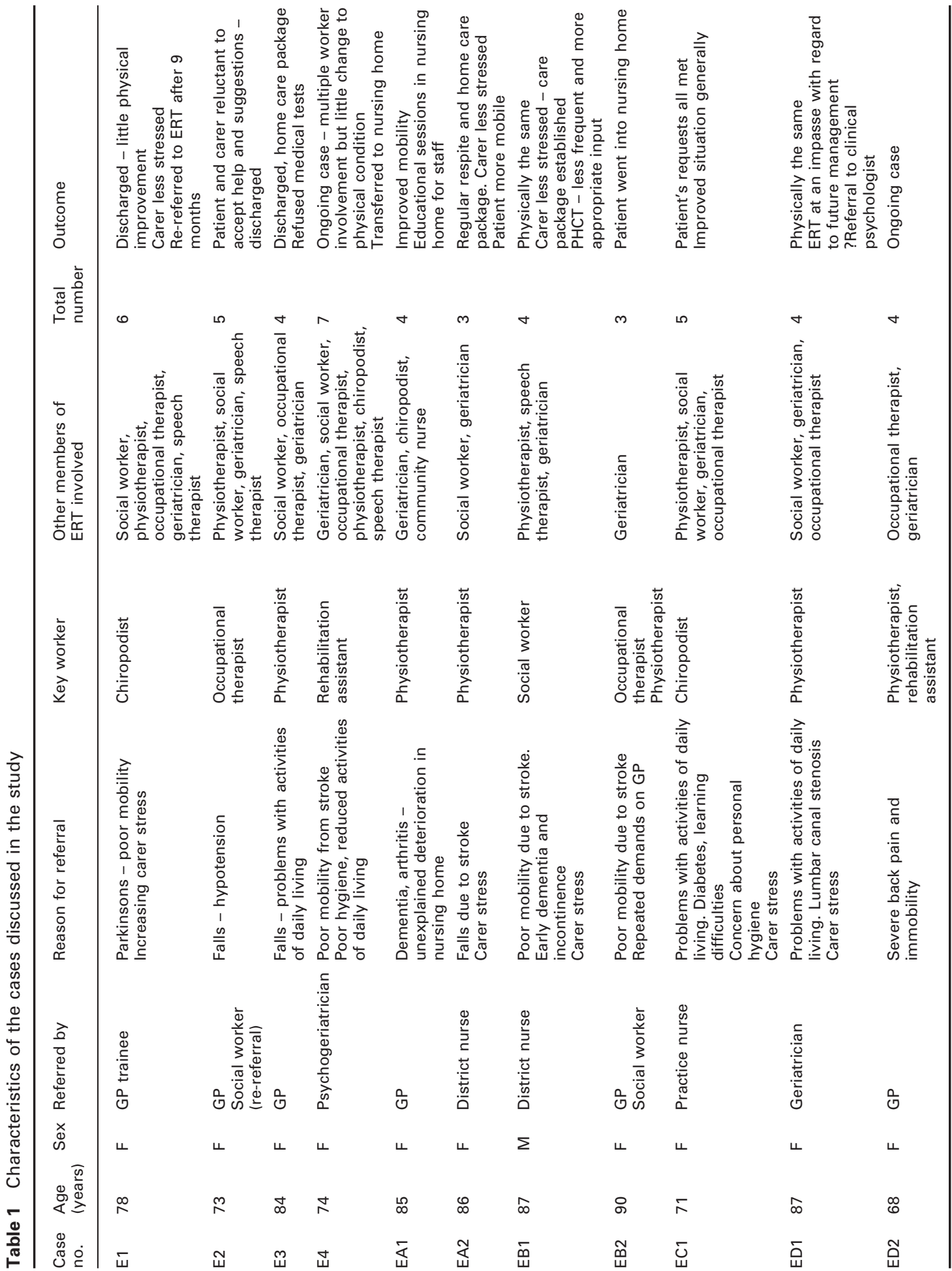

Primary Health Care Research and Development 2000; 1: 163-177 
Table 2 Coding of criticial events: categories, positive points and concerns

\begin{tabular}{|c|c|c|c|}
\hline & Positive points (\%) & Concerns (\%) & Total (\%) \\
\hline \multicolumn{4}{|c|}{ Elderly resource team coding } \\
\hline Clinical care & 88 & 41 & 129 \\
\hline Feelings & 12 & 28 & 40 \\
\hline Communication & 24 & 15 & 39 \\
\hline Professional support & 16 & 6 & 22 \\
\hline Outcomes & 1 & 9 & 10 \\
\hline Administration & 3 & 6 & 9 \\
\hline Total & 144 & 105 & 249 \\
\hline \multicolumn{4}{|l|}{ Patient/carer coding } \\
\hline Patient issues & 10 & 75 & 85 \\
\hline Outcomes & 34 & 9 & 43 \\
\hline Carer issues & 11 & 30 & 41 \\
\hline Total & 55 & 114 & 169 \\
\hline \multicolumn{4}{|c|}{ Primary health care team coding } \\
\hline Clinical care & 21 & 10 & 31 \\
\hline Feelings & 1 & 10 & 11 \\
\hline Communication & 2 & 5 & 7 \\
\hline Outcomes & 5 & 1 & 6 \\
\hline Referral criteria & 2 & 3 & 5 \\
\hline Total & 31 & 29 & 60 \\
\hline \multicolumn{4}{|l|}{ Secondary agencies } \\
\hline & 6 & 12 & 18 \\
\hline Total & 236 & 260 & 496 \\
\hline
\end{tabular}

conflict, psychological distress in informal carers, and inappropriate demands on formal carers (e.g. out-of-hours calls and frequent attendance) (covert reasons for referral; see Box 2).

Caring for this group of patients created a range of negative emotions in formal carers - for example, anger, frustration and despair - which also contributed to referral (see Box 3).

An integrated multidisciplinary approach to care management and the development of a trusted professional role within the team contributed to the context in which role transference occurred. The initial management by the elderly resource team included multidisciplinary assessment, development of an integrated care plan and selection of one member of the team to become the patient's key worker. The latter was responsible for coordinating and overseeing the patient's care plan. Through sustained input on a one-to-one basis and an increasing emotional rapport with the patient, a secure and effective patient-professional relationship ensued with the key worker. The development of this trusted professional role allowed the key worker to engage with the patient's agenda (see
Box 4). This resulted in unexpected breakthroughs in management which had not been achieved by previous carers - for example, the ability of the social worker to eventually persuade a reluctant carer to accept much-needed respite for her husband in a crisis, an outcome which the family's general practitioner and district nurse had been unable to achieve for several years (effective crisis management; see Box 5).

However, on becoming trusted professionals, members of the elderly resource team often felt despondent and frustrated about their cases, like their primary care colleagues before them. This was due to recognition of psychological distress in the patient and an inability of the key worker or team to improve the patient's physical state further (recognition of personal limitations; see Box 6).

Introducing role transference at this point represented a positive approach to a potentially damaging situation, in addition to providing internal support for the key worker. The interactional strategies for carrying out role transference are illustrated in Figure 1. Facilitated reflection of the key worker's (KW1) discomfort and the reasons for it, 
Table 3 Coding of critical events $(n=496)$ : categories and subcategories of areas of concern $(n=260)$

\begin{tabular}{|c|c|c|c|c|c|c|}
\hline Category & $\begin{array}{l}\text { Number } \\
\text { of } \\
\text { events }\end{array}$ & Subcategory (i) & $\begin{array}{l}\text { Number } \\
\text { of } \\
\text { events }\end{array}$ & Subcategory (ii) & $\begin{array}{l}\text { Number } \\
\text { of } \\
\text { events }\end{array}$ & $\begin{array}{l}\text { Example } \\
\text { ( } E=\text { case number } \\
C=\text { area of concern) }\end{array}$ \\
\hline \multirow[t]{8}{*}{$\begin{array}{l}\text { 1. Clinical } \\
\text { management }\end{array}$} & 41 & Patient discharge & 12 & & & $\begin{array}{l}\text { Team not good at } \\
\text { formalizing discharge } \\
\text { procedure (E4, C25)+ }\end{array}$ \\
\hline & & $\begin{array}{l}\text { Role and skills of } \\
\text { individual } \\
\text { members }\end{array}$ & 11 & & 2 & $\begin{array}{l}\text { Physiotherapist } \\
\text { concerned that further } \\
\text { therapeutic } \\
\text { intervention may } \\
\text { produce physical } \\
\text { deterioration (E2, C2) }\end{array}$ \\
\hline & & & & $\begin{array}{l}\text { Role and skills of } \\
\text { key worker }\end{array}$ & 5 & $\begin{array}{l}\text { Key worker put in } \\
\text { inappropriate position } \\
\text { to deal with patient's } \\
\text { severe pain }(\mathrm{E} 3, \mathrm{C} 9)\end{array}$ \\
\hline & & & & $\begin{array}{l}\text { Role and skills of } \\
\text { doctor }\end{array}$ & 2 & $\begin{array}{l}\text { Team unsure about } \\
\text { which doctor to involve } \\
\text { in a crisis (E3, C17) }\end{array}$ \\
\hline & & & & $\begin{array}{l}\text { Role and skills of } \\
\text { rehabilitation } \\
\text { assistant }\end{array}$ & 2 & $\begin{array}{l}\text { Taking on multiple } \\
\text { roles (E4, C13) }\end{array}$ \\
\hline & & $\begin{array}{l}\text { Role and skills of } \\
\text { the team }\end{array}$ & 9 & $\begin{array}{l}\text { Patient } \\
\text { assessment and } \\
\text { management }\end{array}$ & 4 & $\begin{array}{l}\text { Team found patient } \\
\text { difficult to assess (ED2, } \\
\text { C4) }\end{array}$ \\
\hline & & & & $\begin{array}{l}\text { Recognition of } \\
\text { personal } \\
\text { limitations }\end{array}$ & 5 & $\begin{array}{l}\text { Team members have } \\
\text { different levels of } \\
\text { confidence and } \\
\text { experience in } \\
\text { counselling skills (E1, } \\
\text { C16) }\end{array}$ \\
\hline & & $\begin{array}{l}\text { Patient/carer } \\
\text { empowerment }\end{array}$ & 9 & & & $\begin{array}{l}\text { Despite interventions, } \\
\text { patient has not } \\
\text { changed her lifestyle } \\
\text { (EC1, C19) }\end{array}$ \\
\hline \multirow[t]{2}{*}{$\begin{array}{l}\text { 2. Professional } \\
\text { support }\end{array}$} & 6 & Internal support & 5 & & & $\begin{array}{l}\text { Key worker unclear as } \\
\text { to which fellow } \\
\text { professional was her } \\
\text { support (E4, C24) }\end{array}$ \\
\hline & & External support & 1 & & & $\begin{array}{l}\text { District nurse stressed } \\
\text { by patient/family } \\
\text { situation and felt } \\
\text { unsupported (E2, C11) }\end{array}$ \\
\hline
\end{tabular}

+ , refers to coding on original transcript; $\mathrm{E}$, case number; $\mathrm{P} / \mathrm{C}$, positive point or area of concern.

both in formal team meetings and through informal discussion with other team members, led to the emergence of an accessory key worker (KW2) who, through joint visiting and continued discussion with KW1, helped KW1 to accept the discomfort, clarify management dilemmas, and produce a realistic appraisal of the situation (see Box 7). As the equilibrium of the patient-professional relationship was restored, KW2 withdrew to a supporting role.

Reflecting this realistic assessment back to informal and formal carers seemed to validate their subjective 'gut feeling' about the situation. For example, the referring professional often felt that little more could be achieved to improve the patient's condition, but referred them out of frus- 
Box 2 Covert reasons behind patient referral to ERT

\section{Patient-carer conflict}

Case discussion ED1:

Things were steadily getting worse, particularly between the patient and her son ... there was clearly frustration from the son.

(Geriatrician, ERT)

Case discussion EB1:

[Carer] is a very frail, very elderly lady with arthritis who's been struggling to cope with a very large husband, who she's always fought with, he's always hit her, she gives verbal aggravation to and you're watching this crisis build up.

(GP1)

\section{Psychological distress in informal carers}

Case discussion EC1:

[Patient] was moving from the day centre where she'd been for 30 years so that was a huge move for her and she was very anxious about that and I think that possibly started off the anxiety and in constantly going on to her sister, they just couldn't cope, certainly the brother-in-law who was at the end of his tether.

(Social worker, ERT)

Case discussion EB1:

[Wife - main carer] walked out of the house and was contemplating not returning.... The situation was quite desperate. She was very open saying that this has come to a crisis point, he [patient] had to be removed.

(Social worker, ERT)

\section{Inappropriate demands on formal carers}

Case discussion EC1:

She's quite a frequent attender... There was a lot of time involved, probably a lot of the problems were preventable.

(GP5)

She used to come back didn't she on a fairly weekly basis just to go in and have a chat with the practice nurse who was I think very involved.

Case discussion EB1:

(GP1)

Looking back here through the notes, some of my night visits have been because [patient] thumped [carer] and you [GP] have got to tell him not to!

(GP1)

Case discussion EB2:

She was a lady who had crazes on each of us in turn and when you were the subject of her attention you would have large quantities of visits, often very pointless.

(GP1)
Box 3 Negative emotions in formal carers

Case discussion EB2:

Well, I think she was referred probably out of despair... (GP1)

She had a distinct 'feel-bad' factor about her.

Case discussion E2:

We went in quite regularly, I did a lot of visits to try and keep abreast of the situation ... then it seemed she needed assessment medically and that she needed the facilities in hospital and this was a bit of a problem to get her to out-patients ... she failed to attend twice which was very frustrating for everybody.

(Physiotherapist, ERT)

Box 4 Development of the 'trusted professional' role within the ERT

Case discussion E2:

Physiotherapist: We went in quite regularly, I did a lot of visits... encouraged her to use walking aids. Then it seemed that she needed assessment medically and really needed the facilities in hospital and this was a bit of a problem to try to get her up to the $X$-ray unit or to outpatients, and she failed to attend twice, which was very frustrating for everyone... she was suspicious of hospitals.

Social worker: She didn't go out at all really, she was housebound.

Physiotherapist: So eventually we managed to take her there [day centre], escort her and she went quite happily knowing us then and I think she went quite regularly afterwards.

Social worker: It was very helpful that she went with [physiotherapist], she wouldn't have gone with anybody else.

tration, despair or pressure from informal carers. The team's integrated multidisciplinary assessment allowed them to acknowledge the reality of the situation and to feel comfortable about accepting the status quo. Thus mutual professional support seemed to be generated as a consequence of role transference, both within the team and for external agencies (see Box 8).

Primary Health Care Research and Development 2000; 1: 163-177 
Box 5 Effective crisis management

Case discussion EB1:

DN1: I mean she's always been difficult as a carer for accepting help and things in the past, but this was the lowest I've ever seen her. When [social worker from ERT] became involved, to actually put him in for outside care which has never come off before.

GP1: I mean she'd come in sort of really angry that nothing's been done and you offer her all sorts of help in all sorts of guises and she doesn't want it. Consequently you're watching this very frail, very elderly lady with arthritis struggling with a very large husband who she's always fought with and who he's always hit and watching this crisis build up again and again ... I couldn't believe it when I came back from holiday and found he was in respite.

GP2: I went out and tried to bring up the issues that DN1 suggested, but she didn't want any help.

GP1: I think that's where things really became inappropriate, because she had few trusted professionals she felt able to say things to, and whenever we got social services involved there was immediately this barrier, there is no problem.

SW: It was a very sad situation really, but in the end she did benefit from those two weeks in care and she did want him back, but she also accepted that she needed help in caring for him.

DN1: Yes, that was a big breakthrough.

GP1: I mean I wasn't directly involved in this crisis, but it was a family that had to go to crisis and, having gone to crisis, everything had to be put together fairly rapidly and fairly sensitively.

Facilitator: So you mean having the elderly resource team enabled the respite package to be done more quickly?

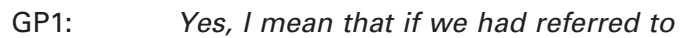
social services, I don't know, I mean my feeling is that it would have taken longer.

DN1: It would have taken longer.

GP1: And it would have been difficult to deliver it as smoothly.
Box 6 Recognition of personal limitations within the ERT

Case discussion E1:

Chiropodist: I did say to her there is so much we can do but I feel you are kind of caught up emotionally, that you're not allowing things to happen but you've got to take courage and go out for a walk... she was blocking all help and change and she hinted at personal problems throughout her life and things she hadn't come to terms with.

Facilitator: Did she say what these were?

Chiropodist: No, and I didn't want to open that door, which is why I wanted her to see a counsellor . . . I said I wasn't the one to help you through them, let me get you someone else.

Facilitator: Do you think you blocked that then?

Chiropodist: Maybe I did, but I felt I was right to. ... She could have ended up in more trouble and I wouldn't have been confident to handle that.

Provision of external support by a specialist team such as the ERT could also have long-term implications for how primary health care teams manage patients with such complex problems. Reflecting a realistic assessment of the patient back to both the patient and their family could in time lead to more appropriate demands on the primary health care team. For example, patients and carers may request inappropriate home visits from their general practitioners through frustration with their disability or social circumstances. If a specialist team sensitively confirms the general practitioner's assessment that there is little more that can be done to improve the patient's circumstances, then the patient and their carers may feel more reassured and consequently modify their demands on the primary health care team. It may also attenuate the negative emotions generated in the professionals and maintain the patient-professional relationship in a more positive equilibrium.

A further consequence of role transference was the generation of a satisfactory and negotiated discharge (constructive discharge; see Box 9). This was achieved through the gradual introduction of an informal or formal carer into the trusted professional role, with simultaneous withdrawal of 


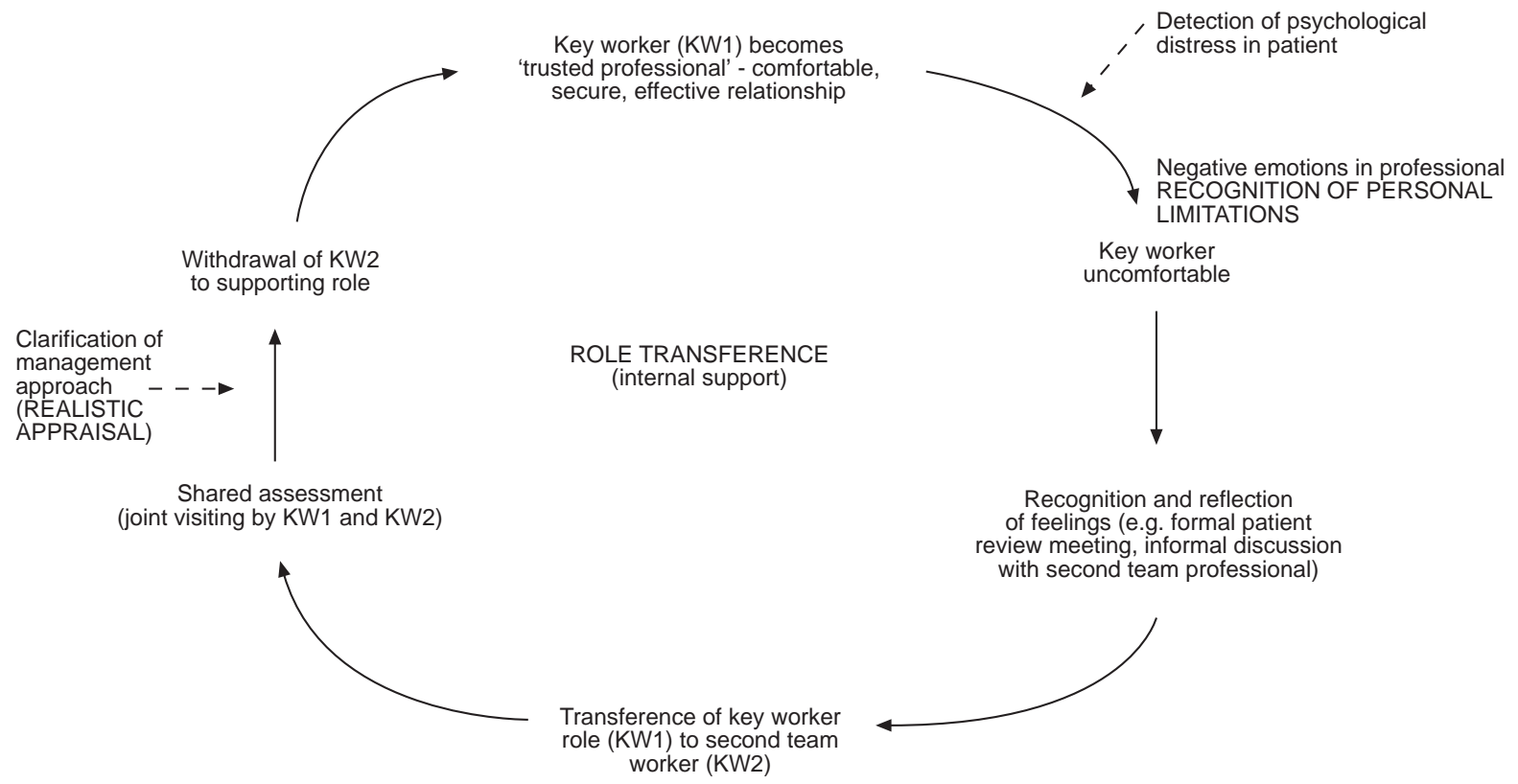

Figure 1 Interactional strategies to ensure effective role transference.

Box 7 Realistic appraisal of the patient

Case discussion E1:

I think that's why it wasn't a success in the conventional way, because all of us in our own disciplines and as a team could see very concrete things that could be done at the beginning which would have improved the situation, but within a few weeks of trying to achieve these aims it was obvious that it was not going to happen. (Occupational therapist, ERT)

Case discussion E3:

She had been housebound for three years, so we knew that any sort of rehabilitation was going to be limited to getting her back to probably what she was like a few weeks before rather than three years before.

(Physiotherapist, ERT)

resource team input, and through discussion with them of the positive outcomes and realistic appraisal of the case.

A conceptual model was devised to show the relationship between role transference, its causal conditions, the context in which it occurred, the interactional strategies required to carry it out and the resulting outcomes (see Figure 2).
Box 8 Mutual professional support

Case discussion ED1:

Facilitator: And you've established that your feelings are the same as the primary health care team?

Social worker: It would have been interesting to have this at an earlier stage, I think that would have been useful.

Nurse: I think this is really helpful, you know I've found out a lot today, hearing different perspectives, because it makes you feel better about yourself.

\section{Discussion}

This critical event study of patient referrals to a community-based elderly assessment and management team yielded an inductive classification of categories and subcategories considered to be important in their management approach. Following a grounded theory paradigm (Strauss and Corbin, 1990), specific concepts embedded in the data were linked to create a model to describe the process of care delivered. Multidisciplinary teams 


\begin{tabular}{|c|c|}
\hline \multicolumn{2}{|c|}{$\begin{array}{l}\text { Box } 9 \text { Generating a constructive patient dis- } \\
\text { charge by the ERT }\end{array}$} \\
\hline \multicolumn{2}{|c|}{ Case discussion E4: } \\
\hline $\begin{array}{l}\text { Rehabilitation } \\
\text { assistant: }\end{array}$ & $\begin{array}{l}\text { I think we've acted as a first link } \\
\text { for [patient]. }\end{array}$ \\
\hline Facilitator: & $\begin{array}{l}\text { So that needs to be replaced if } \\
\text { you're going to withdraw. }\end{array}$ \\
\hline $\begin{array}{l}\text { Rehabilitation } \\
\text { assistant: }\end{array}$ & $\begin{array}{l}\text { Yes, I think it has in the home } \\
\text { care now and she has her care } \\
\text { alarm. }\end{array}$ \\
\hline Social worker: & $\begin{array}{l}\text { And she certainly has a very } \\
\text { supporting daughter. }\end{array}$ \\
\hline $\begin{array}{l}\text { Case discussior } \\
\text { Social worker: }\end{array}$ & $\begin{array}{l}\text { EC1: } \\
\text { I think because the primary } \\
\text { health care team particularly } \\
\text { have been so involved and are } \\
\text { willing to take that on again, I } \\
\text { think it's very appropriate for us } \\
\text { to withdraw... and because } \\
\text { there are such good links with } \\
\text { [day centre]. We've had meetings } \\
\text { with the district nurse and } \\
\text { primary key worker at [day } \\
\text { centre] so there's a lot of } \\
\text { monitoring. }\end{array}$ \\
\hline
\end{tabular}

are being increasingly employed in the management of chronic illness and disability (Mellor and Solomon, 1992). Such teams, like the elderly resource team in this study, will work across clinical and social boundaries, and may specialize in one particular problem (e.g. multiple sclerosis), but will probably receive referrals with the same complex physical, psychological and social needs as the frail, elderly population in this study. The conceptual model developed represents an example of substantive theory, a theoretical representation of one team in one particular context (Strauss and Corbin, 1990), because it pertains to the elderly resource team and their management of a particular group of patients (significant cases). This unfortunately limits its transferability to similar rehabilitation teams.

Other limitations of this qualitative study are acknowledged. One specific type of nonprobability sampling used in a grounded theory approach is 'theoretical sampling', in which the developing theory, obtained through initial analysis of the data, guides the process of further sampling. The use of the critical incident technique restricted this with cases selected through participants' rating of their significance. However, the last two cases were theoretically selected to test the developed model, and the facilitator revisited all the transcripts at the end of the study to ensure the applicability of the theory. The validity of the theory could have been further enhanced by extending the study period in order to seek divergent cases, and by triangulation (by collecting data from other sources such as focus groups with the nonparticipating practices and other referral agencies).

A total of 496 events were generated from discussion of 11 cases (a mean of 45 events per case). Flanagan (1954) referred to studies which generated over 700 critical incidents in the analysis of behavioural data. However, it seems from this and other similar critical incident studies in primary care (Bradley, 1992a; Spencer et al., 1995) that, in practice, a smaller number is sufficient to provide a classification of relevant factors and to meet the time constraints imposed by clinical practice. According to Flanagan's recommendations (Flanagan, 1954), for an incident to have high content or face validity, the data must be collected from all involved. Unfortunately, due to following previously published guidelines (Robinson et al., 1995) and limiting the maximum group size to 12 , only clinical representatives from primary health care teams attended the combined discussions. Receptionists and practice managers may also possess relevant and in-depth knowledge of patients living with chronic illness and the feelings and stress experienced by their informal carers, and this inadvertent omission would have reduced the validity of the data. In theory, patients and their main carers should also have attended the discussions, but this might have had implications for the process and outcome of the study. Professionals may feel uncomfortable about admitting potential errors to such an audience, and patients may lack perspective regarding the aim of the activity, and show a tendency to focus on personal and attitudinal factors rather than effective behaviour.

Educational theory states that adults learn more appropriately and effectively through reflection on actual personal experience, rather than through the application of established theory (Kolb, 1984; Schon, 1991). The latter is termed the 'model of technical rationality' where problem-solving is achieved through rigorous and relevant application of scientific theory. However, this model fails to account for the way in which professionals cope 


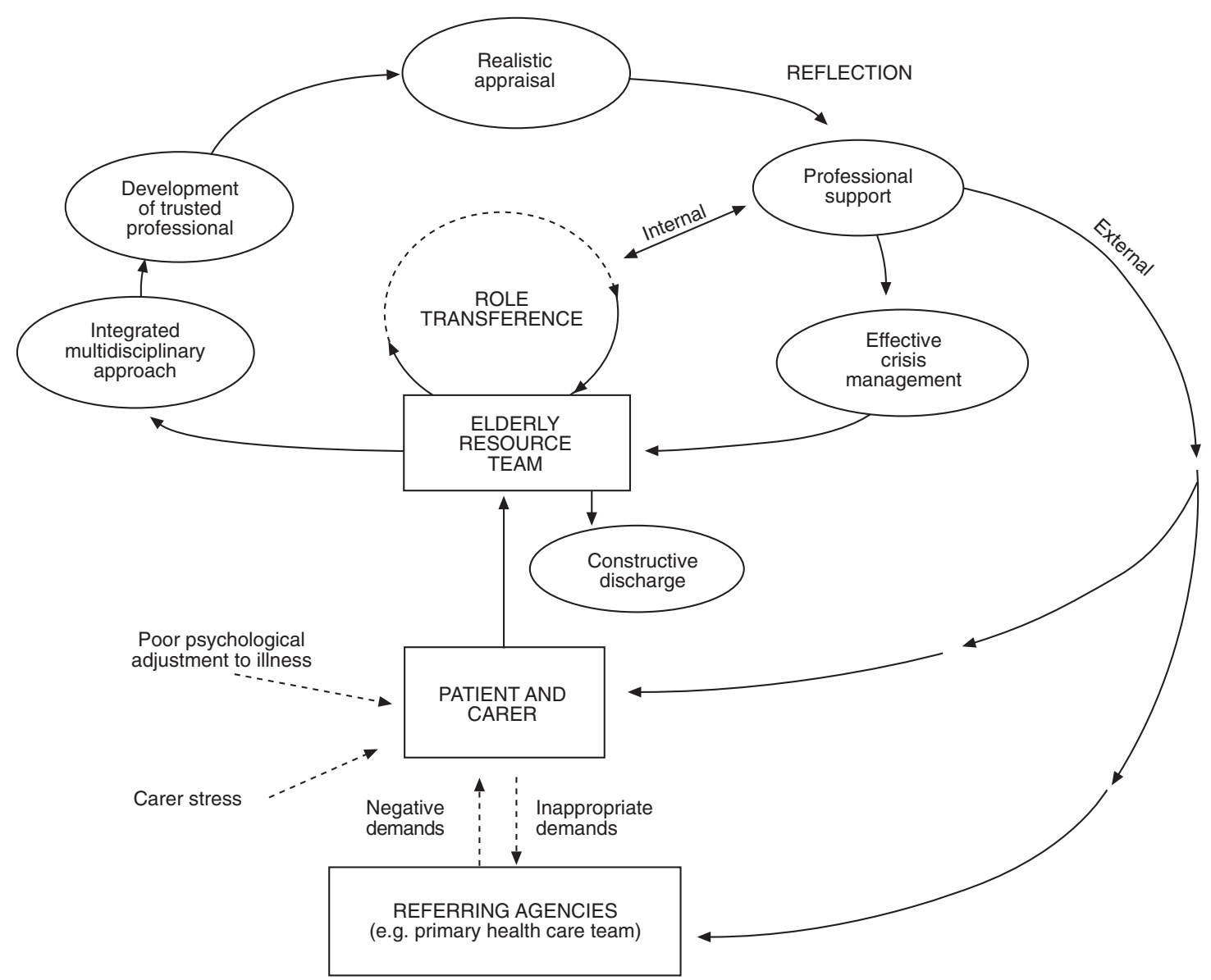

Figure 2 A conceptual model to explain the theoretical basis of the ERT.

in critical or 'divergent' situations where they experience uncertainty, complexity or uniqueness. In such situations the epistemology of practice is implicit in an artistic or intuitive informal process termed 'reflection in action' (Schon, 1991). In contrast to the model of technical rationality, the concept of reflection in action focuses on problemsetting - that is, the process by which professionals determine the decisions to be made and the outcomes to be achieved, and frame the context in which these will occur - rather than on problemsolving alone. Recent research on team functioning has focused on this concept of reflexivity, or the way in which team members consciously critique the process of their work, as a key factor in developing effective teams, and the fact that teams require time and support to review not just their cases but also their team functioning (Opie, 1997). The use of critical or significant event analysis affords potential for stimulating reflexivity in teams because it looks at both the method of care management and the process by which it is achieved. Discussion of cases with the ERT alone generated a higher mean number of events per case (58 per case) than in combined discussion with the practice (38 per case). The ERT was established 2 years prior to the start of the study, and from the facilitator's observations had already created a cohesive team, working in a safe and open environment, conducive to reflective practice. The team members in this study have subsequently enhanced their level of reflexivity by continuing to detect further critical incidents, including one discussion which involved participants from both hospital and 
community care teams in addition to primary health care teams.

One factor identified in previous research as contributing to the successful development of a multidisciplinary geriatric programme is the presence of formal institutional support within teams (Roberts et al., 1994). This study confirms that finding. Patients were referred for covert reasons for example, negative emotions such as anger and frustration in formal carers, and inappropriate demands on health and social care systems. The same feelings were often mirrored in the elderly resource team, but were dealt with informally and haphazardly within the current structure. Specialist teams should have formal inbuilt mechanisms in place from their creation, in order to recognize, reflect on and manage such problems. In this study, reflection of a realistic appraisal of patients' complex problems back to referring agencies generated a degree of external support. Strategies such as the model of role transference could be taught to primary health care teams in order to provide a source of internal support and help general practitioners to care for this group of emotionally demanding patients on a long-term basis. In discussing significant/critical cases, members of the ERT often felt that they had achieved 'little' in terms of patient outcomes despite extensive input, yet analysis of the data revealed a largely positive balance of events in the patient/carer outcomes category, with the majority related to patient/carer satisfaction. Reviewing cases in this way may prevent the use of terms such as 'heartsink' and 'difficult' being attached to patients, and allow teams to develop a more positive attitude towards them.

Research carried out at McMaster University revealed that patients living with chronic illness and disability are high users of health and social services, but in an unco-ordinated manner, and that this was not related to the extent of their physical disabilities, but to their poor psychological adaptation to their illness or disability (Browne et al., 1995). By the end of the study, the ERT felt that they were detecting psychological problems in patients at a much earlier stage and referring the patient for psychological assessment. In one case, the occupational therapist was working in conjunction with a clinical psychologist in an attempt to improve the patient's physical state.

This qualitative study has described the process by which one community-based, multidisciplinary resource team worked. Further qualitative research is required that replicates the study using different teams and different clinical settings to test the validity of the developed theory. In addition, a quantitative study designed to evaluate whether the input from such specialist multidisciplinary teams leads to changes in patients' morbidity and quality of life, and in the use of health care resources, may reveal how cost-effective as well as clinically effective these teams are compared to traditional methods of secondary care.

\section{Acknowledgements}

We should like to thank all the participants in the study (the elderly resource team and the four primary health care teams). We are also grateful to Sharon Denley for secretarial assistance and Ann Crosland for acting as an independent reviewer. LR would like to thank Joe Kai and Pauline Pearson for helpful comments on the manuscript. This study was made possible by a grant from Newcastle and North Tyneside Health Authority.

\section{References}

Baker, R., Robertson, N. and Farooqi, A. 1995: Audit in general practice: factors influencing participation. British Medical Journal 311, 31-34.

Benner, P. 1984: From novice to expert: excellence and power in clinical nursing practice. Menlo Park, CA: Addison Wesley.

Berlin, A., Spencer, J.A., Bhopal, R.S. and Zwanenberg, T.V. 1992: Audit of deaths in general practice: a pilot study of the critical incident technique. Quality in Health Care 1, 231-35.

Bradley, C.P. 1992a: Turning anecdotes into data - the critical incident technique. Family Practice 9, 98-103.

Bradley, C.P. 1992b: Uncomfortable prescribing decisions: a critical incident study. British Medical Journal 304, 294-96.

Browne, G.E., Roberts, J., Byrne, C. et al. 1995: More effective and less expensive community approaches to care of chronically ill. Working Paper Series 95-12. Hamilton, Ontario: McMaster University, Services-Linked Research Unit on Health and Social Services Utilisation.

Department of Health 1990: Caring for people - community care

Primary Health Care Research and Development 2000; 1: 163-177 
in the next decade and beyond. London: Department of Health.

Dunn, W.R. and Hamilton, D.D. 1986: The critical incident technique - a brief guide. Medical Teacher 8, 207-15.

Flanagan, J.C. 1954: The critical incident technique. Psychological Bulletin 51, 327-58.

Gregson, B.A., Cartlidge, A. and Bond, J. 1991: Interprofessional collaboration in primary health care organizations. London: Royal College of General Practitioners.

Kolb, D.A. 1984: Experiential learning: an experience as the source of learning and development. Englewood Cliffs, NJ: Prentice Hall.

MacMahon, D.G. 1994: The health input into community care. Journal of the British Association for Service to the Elderly 342, 1032-36.

Mellor, M.J. and Solomon, R. 1992: The interdisciplinary geriatric/gerontological team in the academic setting: hot air or energiser? Geriatric Social Work Education 18, 203-15.

National Health Service Executive 1994: Towards a primary care-led NHS. London: Department of Health.

Norman, I.J., Redfern, S.J., Tomalin, D.A. et al. 1992: Developing Flanagan's critical incident technique to elicit indications of high and low quality nursing care from patients and their nurses. Journal of Advanced Nursing 17, 590-600.

Opie, A. 1997: Thinking teams, thinking clients: issues of discourse and representation in the work of health care teams. Sociology of Health and Illness 19, 259-80.

Pringle, M., Bradley, C., Carmichael, C.M., Wallis, H. and Moore, A. 1995: Significant event auditing. A study of the feasibility and potential of case-based auditing in primary medical care. Occasional Paper No. 70. Exeter: Royal College of General Practitioners.

Roberts, K., Wright, J., Thibault, J., Stewart, A.V. and Knapp, K. 1994: Geriatric partnerships in health and care: the life span model. Educational Gerontology 20, 115-28.

Robinson, L., Stacy, R., Spencer, J. and Bhopal, R. 1995: How to do it - use of facilitated case discussions for significant event audit. British Medical Journal 311, 315-18.

Sands, R. 1993: Can you overlap here? A question for interdisciplinary teams. Discourse Processes 16, 545-64.

Schon, D.A. 1991: The reflective practitioner. How professionals think in action. Aldershot: Ashgate Publishing.

Spencer, J.A., Stacy, R., Robinson, L., Berlin, A. and Bhopal, R.S. 1995: Audit of death in general practice. A report of a study into the development and evaluation of death registers and facilitated case discussions. Newcastle upon Tyne: University of Newcastle upon Tyne, Department of Primary Health Care.

Standing Medical Advisory Committee 1990: The quality of medical care. London: HMSO.

Strauss, A.L. and Corbin, J. 1990: Basics of qualitative research. Grounded theory procedure and techniques. London: Sage.

Stuck, A.E., Siv, A.L., Wieland, G.D. and Adams, J. 1993: Comprehensive geriatric assessment - a meta-analysis of controlled trials. Lancet 342, 1032-36.

Waterston, T. 1988: A critical incident study in child health. Medical Education 22, 27-31.
Working Group of the Royal College of Physicians Rehabilitation Medicine Committee 1997: Model for the organisation of a community-based rehabilitation service. Journal of the Royal College of Physicians 5, 503-5.

\section{Appendix 1 Analysis of events in part of a transcript from study 2}

Social worker:

Physiotherapist:

Where you see a very frail, elderly woman falling regularly, possibly at risk from these falls, obviously injuring herself, and going in and out of that situation on a fairly regular basis and not being able to do anything about it, I think there was a lot of stress (C1 - ERT; feelings within the team) and maybe she just needed the reassurance ... but there was a change, your [physio] intervention certainly produced a change (P1 patient outcome, improvement in physical state).

We went in quite regularly, I did a lot of visits ... encouraged her to use the walking aids (P2 - Elderly resource team: role of the key worker). Then it seemed that she needed assessment medically and really needed the facilities in hospital and this was a bit of a problem to try to get her up to the ... unit or to out-patients and she failed to attend twice, which was very frustrating for everyone (C2 - elderly resource team - feelings of the team) because without knowing exactly what the problem was it was difficult to help the ongoing failing situation and so we tried really hard to get her there ... she was so suspicious of hospital.

Primary Health Care Research and Development 2000; 1: 163-177 
Social worker: She didn't go out at all really, she was housebound.

Physiotherapist: So eventually we managed to take her there, escort her and she went happily knowing us then and I think she went regularly (P3 - elderly

resource team; role and skills

of key worker, 'trusted

$\mathrm{P}=$ positive point.

$\mathrm{C}=$ area of concern. 